\title{
Update on targeted therapies for advanced non-small cell lung cancer: nivolumab in context
}

\author{
This article was published in the following Dove Press journal: \\ Therapeutics and Clinical Risk Management \\ 21 February 2017 \\ Number of times this article has been viewed
}

\author{
Alexander D Le ${ }^{1, *}$ \\ Saeed K Alzghari ${ }^{2, *}$ \\ Gary W Jean ${ }^{2}$ \\ Ninh M La-Beck' \\ 'Department of Immunotherapeutics \\ and Biotechnology, School of \\ Pharmacy, Texas Tech University \\ Health Sciences Center, Abilene, \\ 2Department of Pharmacy Practice, \\ School of Pharmacy, Texas Tech \\ University Health Sciences Center, \\ Dallas, TX, USA \\ *These authors contributed equally \\ to this work
}

\begin{abstract}
While the initial treatment of non-small cell lung cancer (NSCLC) usually relies on surgical resection followed by systemic cytotoxic chemotherapy and/or radiation therapy, recent advances in understanding of NSCLC biology and immunology have spurred the development of numerous targeted therapies. In particular, a class of immune modulatory drugs targeting the immune checkpoint pathways has demonstrated remarkable durable remissions in a select minority of advanced NSCLC patients, potentially heralding the elusive "cancer cure". This review focuses on the clinical evidence for one of these agents, nivolumab, and clarifies the role of this drug in the context of the other targeted therapies currently available for the treatment of NSCLC. We also discuss the impact of nivolumab on patient quality of life and health economics.
\end{abstract}

Keywords: nivolumab, lung cancer, immune checkpoint, targeted therapy

\section{Introduction}

Lung cancer continues to be one of the top five causes of cancer-related mortality, with non-small cell lung cancer (NSCLC) being the most common subtype. This category is subdivided further based on pathology into adenocarcinoma and squamous-cell and largecell NSCLC. When diagnosed early (stage I and stage II NSCLC) and surgically resectable, it generally has a good prognosis. However, the treatment of advanced, recurrent, and metastatic NSCLC is often associated with significantly poorer prognosis. While the firstline treatment consists of surgery followed by systemic cytotoxic chemotherapy, and/or radiation therapy, recent advances in understanding of cancer biology and immunology have spurred the development of numerous targeted therapies (Figure 1) with the potential to dramatically improve overall survival (OS) in specific NSCLC populations. ${ }^{1}$ Several of these targeted agents are linked to genomic abnormalities in the tumor tissue, and it has now become part of the standard of care to test patients who are candidates for systemic drug therapies for the presence of such mutations. ${ }^{1}$ More recently, a class of immune modulatory drugs targeting the immunoinhibitory (ie, immune checkpoint) pathways has demonstrated remarkable durable remissions in a select minority of advanced NSCLC patients, potentially heralding the elusive "cancer cure". This review focuses on the clinical evidence for one of these agents, nivolumab, and clarifies the role of this drug in the context of the other targeted therapies (Tables 1 and 2) currently available for the treatment of NSCLC. We also discuss the impact of nivolumab on patient quality of life and health economics.

\section{Epidermal growth factor receptor (EGFR)-targeted therapies}

One of the first therapeutic targets in NSCLC is the EGFR, a tyrosine kinase receptor, which typically plays a role in promoting epidermal growth, organogenesis, and 


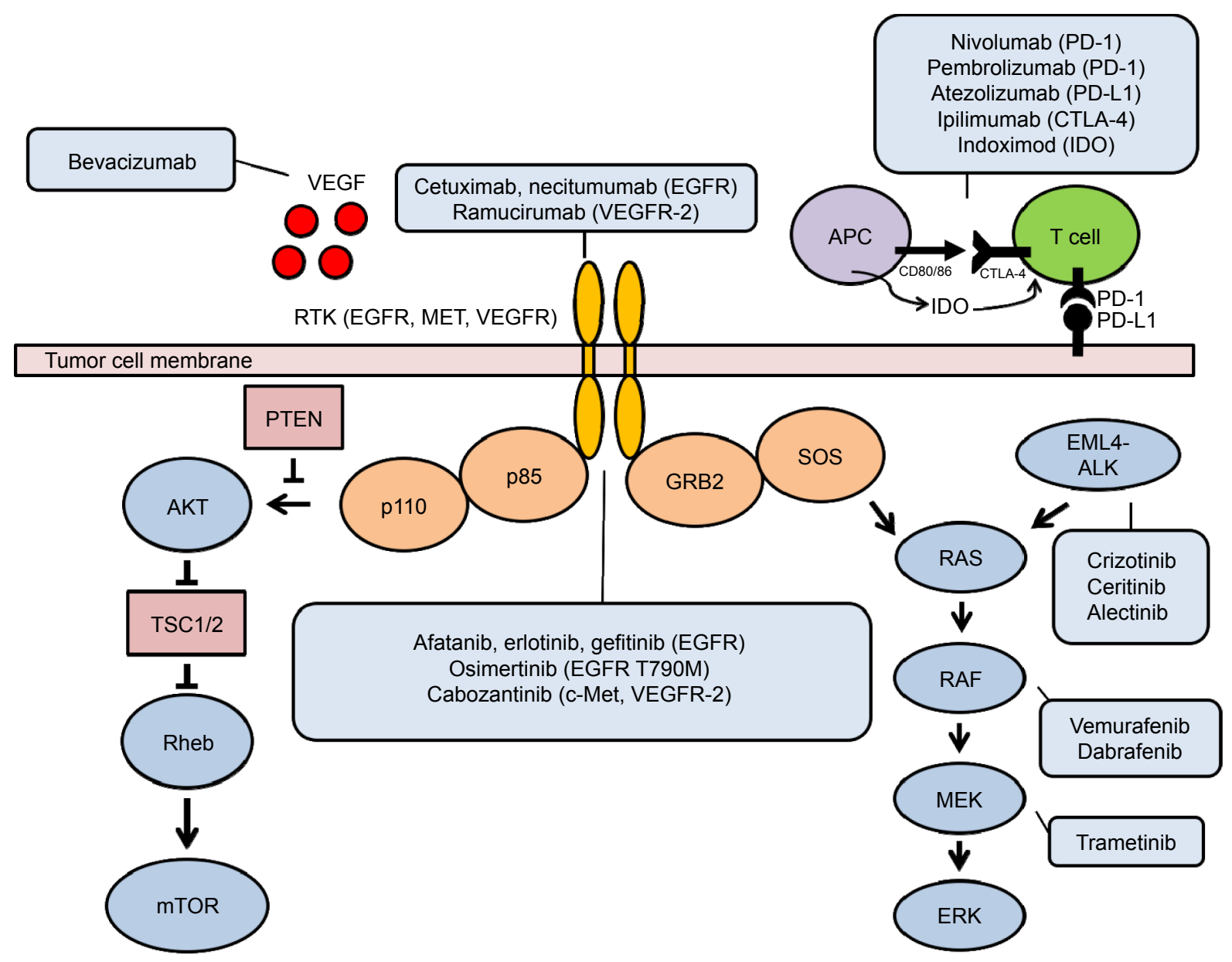

Figure I Molecular targets in NSCLC.

Abbreviations: AKT, protein kinase B; ALK, anaplastic lymphoma kinase; CD, cluster of differentiation; c-Met, cellular mesenchymal to epithelial transition factor; CTLA-4, cytotoxic T-lymphocyte-associated molecule 4; EGFR, epidermal growth factor receptor; EML4, echinoderm microtubule-associated protein-like 4; ERK, extracellular signalregulated kinase; GRB2, growth factor receptor-bound protein 2; IDO, indoleamine 2,3-dioxygenase; MEK, MAPK/ERK kinase; mTOR, mechanistic target of rapamycin; NSCLC, non-small cell lung cancer; p85/pI I0, phosphoinositide 3-kinase; PD-I, programmed cell death I; PTEN, phosphatase and tensin homolog; RAF, rapidly accelerated fibrosarcoma; RAS, human rat sarcoma protein; Rheb, Ras homolog enriched in brain; RTK, receptor tyrosine kinase; SOS, son of sevenless; T790M, EGFR Thr790Met mutation; TSC I/2, tuberous sclerosis proteins I and 2; VEGF, vascular endothelial growth factor; VEGFR, VEGF receptor.

proliferation. In some patients, EGFR is overexpressed in tumors suggesting that it may play a role in driving tumor progression, and it has proven to be an important target in the treatment of colorectal and other cancers. ${ }^{2}$ However, in NSCLC, EGFR overexpression alone did not correlate with response to therapy, and rather it was the presence of specific EGFR mutations in tumors that predicted therapeutic benefits. Approximately $15 \%$ of Caucasian patients and up to $40 \%$ of Asian patients have EGFR-mutated tumors. Up to $90 \%$ of these are mutations in exons 19 and 21, resulting in a constitutively active tyrosine kinase. Interestingly, EGFR-mutated NSCLC is most common in Asian women who have never been smokers and appears to be mutually exclusive of other oncogenic mutations such as anaplastic lymphoma kinase (ALK) aberrations in tyrosine kinase inhibitor (TKI)-naive patients. The EGFR inhibitors are composed of two classes of therapeutics: monoclonal antibodies and small molecule TKIs. In general, they have been shown to improve objective response rates (ORRs) and progression-free survival (PFS) rates and were associated with better patient quality of life and tolerability than cytotoxic chemotherapy. The monoclonal antibodies targeting EGFR have only been studied in an unselected advanced NSCLC population and did not appear to be as efficacious as the TKIs; however, there have been no head-to-head studies. The TKIs are indicated for advanced NSCLC patients having the EGFR-sensitizing mutations in exon 19 or 21 . However, the majority of patients who initially respond will develop drug resistance within 12 months, which limits the utility of this class of drugs for long-term therapy. 3,4

\section{Monoclonal antibodies targeting EGFR}

\section{Cetuximab}

Cetuximab (Erbitux ${ }^{\circledR}$; Eli Lilly and Company, Indianapolis, IN, USA), a monoclonal antibody targeting EGFR approved 
Table I Targeted therapies approved for NSCLC

\begin{tabular}{|c|c|c|c|}
\hline Agent & Target & Class & FDA approval date and NSCLC indication \\
\hline Erlotinib & EGFR & TKI & $\begin{array}{l}\text { 2013; first-line treatment for NSCLC whose tumors have EGFR exon } 19 \text { deletions } \\
\text { or exon 2I (L858R) substitution mutations as detected by an FDA-approved test } \\
\text { No longer approved for maintenance treatment }(2010) \text { or second-line treatment } \\
\text { (2004) of NSCLC patients who do not have the above EGFR mutations }\end{array}$ \\
\hline Bevacizumab & VEGF & IgGI, humanized & $\begin{array}{l}\text { 2006; NSCLC, with carboplatin and paclitaxel for first-line treatment of } \\
\text { unresectable, locally advanced, recurrent or metastatic disease }\end{array}$ \\
\hline Crizotinib & $\begin{array}{l}\text { ALK } \\
\text { ROSI }\end{array}$ & TKI & $\begin{array}{l}\text { 201 I; locally advanced or metastatic NSCLC that is ALK-positive as detected by an } \\
\text { FDA-approved test } \\
\text { 2016; metastatic NSCLC that is ROSI-mutation positive }\end{array}$ \\
\hline Afatanib & EGFR & TKI & $\begin{array}{l}\text { 2013; metastatic NSCLC whose tumors have EGFR exon } 19 \text { deletions or exon } 21 \\
\text { (L858R) substitution mutations as detected by an FDA-approved test }\end{array}$ \\
\hline Ceritinib & ALK & TKI & $\begin{array}{l}\text { 2014; ALK-positive metastatic NSCLC who have progressed on or are intolerant } \\
\text { to crizotinib }\end{array}$ \\
\hline Ramucirumab & VEGFR-2 & $\operatorname{lgGI}$, human & $\begin{array}{l}\text { 20I4; in combination with docetaxel for the treatment of patients with metastatic } \\
\text { NSCLC with disease progression on or after platinum-based chemotherapy }\end{array}$ \\
\hline Alectinib & ALK & TKI & $\begin{array}{l}\text { 2015; ALK-positive, metastatic NSCLC who have progressed on or are intolerant } \\
\text { to crizotinib }\end{array}$ \\
\hline Gefitinib & EGFR & TKI & $\begin{array}{l}\text { 2015; metastatic NSCLC whose tumors have EGFR exon } 19 \text { deletions or exon } 21 \\
\text { (L858R) substitution mutations as detected by an FDA-approved test }\end{array}$ \\
\hline Necitumumab & EGFR & $\operatorname{lgGI}$, human & $\begin{array}{l}\text { 2015; indicated in combination with gemcitabine and cisplatin for the first-line } \\
\text { treatment of patients with metastatic squamous NSCLC }\end{array}$ \\
\hline Osimertinib & $\begin{array}{l}\text { EGFR } \\
\text { T790M }\end{array}$ & TKI & $\begin{array}{l}\text { 2015; metastatic EGFR T790M mutation-positive NSCLC as detected by an } \\
\text { FDA-approved test, who have progressed on or after EGFR TKI therapy }\end{array}$ \\
\hline Nivolumab & PD-I & $\operatorname{lgG} 4$, human & $\begin{array}{l}\text { 20I5; metastatic NSCLC and progression on or after platinum-based chemotherapy. } \\
\text { Patients with EGFR or ALK genomic tumor aberrations should have disease } \\
\text { progression on FDA-approved therapy for these aberrations prior to receiving } \\
\text { nivolumab }\end{array}$ \\
\hline Pembrolizumab & PD-I & IgG4, humanized & $\begin{array}{l}\text { 20I5; metastatic NSCLC whose tumors express PD-LI (tumor proportion } \\
\text { score } \geq 1 \% \text { ) as determined by an FDA-approved test and who have disease } \\
\text { progression on or after platinum-containing chemotherapy } \\
2016 \text {; first-line treatment of metastatic NSCLC whose tumors have high PD-LI } \\
\text { expression (tumor proportion score } \geq 50 \% \text { ) as determined by an FDA-approved test } \\
\text { (Patients with EGFR or ALK genomic tumor aberrations should have disease } \\
\text { progression on FDA-approved therapy for these aberrations prior to receiving } \\
\text { pembrolizumab.) }\end{array}$ \\
\hline Atezolizumab & PD-LI & IgGI, humanized & $\begin{array}{l}\text { 2016; metastatic NSCLC and progression on or after platinum-based chemotherapy. } \\
\text { Patients with EGFR or ALK genomic tumor aberrations should have disease } \\
\text { progression on FDA-approved therapy for these aberrations prior to receiving } \\
\text { atezolizumab }\end{array}$ \\
\hline
\end{tabular}

Abbreviations: ALK, anaplastic lymphoma kinase; EGFR, epidermal growth factor receptor; FDA, US Food and Drug Administration; lgG, immunoglobulin G; NSCLC, non-small cell lung cancer; PD-I, programmed cell death I receptor; PD-LI, programmed death-ligand I; ROSI, receptor of silencing I; TKI, tyrosine kinase inhibitor; VEGF, vascular endothelial growth factor; VEGFR, VEGF receptor.

for head and neck cancers as well as colorectal cancer, has shown activity in patients with NSCLC. ${ }^{5}$ The First-Line Erbitux in Lung Cancer (FLEX) trial was a multinational, multicenter, open-label, Phase III study of 1,125 patients with wet stage IIIB or stage IV NSCLC. ${ }^{6}$ The addition of cetuximab to chemotherapy (cisplatin and vinorelbine) versus chemotherapy alone showed a minor but significant improvement in OS. ${ }^{6}$ The median OS was 11.3 months for patients treated with chemotherapy and cetuximab versus 10.1 months for patients treated with chemotherapy alone (hazard ratio $[\mathrm{HR}]=0.871,95 \%$ confidence interval $[\mathrm{CI}]: 0.762-0.996$, $P=0.044) .{ }^{6}$ Rash was the main adverse event experienced with patients on cetuximab. ${ }^{6}$ Although the results of this study were statistically significant, a separate study found no difference between chemotherapy alone and chemotherapy with the addition of cetuximab, and the US Food and Drug Administration (FDA) has not approved cetuximab for any indication involving NSCLC.

\section{Necitumumab}

Necitumumab (Portrazza ${ }^{\circledR}$; Eli Lilly and Company) is an anti-EGFR recombinant human monoclonal antibody indicated, in combination with gemcitabine and cisplatin, for the first-line treatment of patients with metastatic squamous NSCLC originally approved in $2015 .{ }^{7}$ The FDA-approved dose is $800 \mathrm{mg}$ intravenous (IV) over 60 minutes on days 1 
Table 2 Trials leading to FDA approval of targeted therapies for advanced NSCLC

\begin{tabular}{|c|c|c|c|c|c|c|c|c|c|}
\hline Reference & Phase & $\begin{array}{l}\text { Subjects } \\
\text { (N) }\end{array}$ & Setting & Regimen & Comparison arm & Target & $\begin{array}{l}\text { Median } \\
\text { PFS }\end{array}$ & $\begin{array}{l}\text { Median } \\
\text { OS }\end{array}$ & $\begin{array}{l}\text { ORR } \\
\text { (\%) }\end{array}$ \\
\hline 10 & III & 731 & Second or third line & Erlotinib & Placebo & EGFR & 2.2 & 6.7 & 8.9 \\
\hline II & III & 889 & $\begin{array}{l}\text { Maintenance after four } \\
\text { cycles of platinum- } \\
\text { based chemotherapy }\end{array}$ & Erlotinib & Placebo & EGFR & 3.1 & 12.0 & 11.9 \\
\hline 12 & III & 174 & First line & $\begin{array}{l}\text { Erlotinib + cisplatin (or } \\
\text { carboplatin) + docetaxel } \\
\text { (or gemcitabine) }\end{array}$ & $\begin{array}{l}\text { Cisplatin (or carboplatin) + } \\
\text { docetaxel (or gemcitabine) }\end{array}$ & EGFR & 9.7 & 19.3 & 58 \\
\hline 5 & III & 878 & First line & $\begin{array}{l}\text { Bevacizumab + } \\
\text { carboplatin + paclitaxel }\end{array}$ & Carboplatin + paclitaxel & VEGF & 6.2 & 12.3 & 35 \\
\hline 26 & I & 116 & First line & Crizotinib & None & ALK & - & - & 61 \\
\hline 26 & II & 135 & Second line & Crizotinib & None & ALK & - & - & 50 \\
\hline 29 & I & 50 & First or second line & Crizotinib & None & ROSI & 19.2 & - & 72 \\
\hline 18 & III & 364 & First line & Afatanib & Cisplatin + gemcitabine & EGFR & II & 22.1 & 66.9 \\
\hline 30 & I & 163 & Second line & Ceritinib & None & ALK & 8.3 & 16.7 & 56 \\
\hline 33 & II & 1,253 & Second line & $\begin{array}{l}\text { Ramucirumab + } \\
\text { docetaxel }\end{array}$ & Docetaxel & VEGFR-2 & 4.5 & 10.5 & 23 \\
\hline 31 & II & 87 & Second line & Alectinib & None & ALK & 8.1 & - & 52 \\
\hline 23 & II & 138 & Second line & Alectinib & None & ALK & 8.9 & - & 50 \\
\hline 15 & IV & 106 & First line & Gefitinib & None & EGFR & 9.7 & 19.2 & 69.8 \\
\hline 8 & III & I,093 & First line & $\begin{array}{l}\text { Necitumumab }+ \\
\text { cisplatin }+ \text { gemcitabine }\end{array}$ & Cisplatin + gemcitabine & EGFR & 5.7 & 11.5 & 31 \\
\hline 21 & II & 411 & Second line & Osimertinib & None & $\begin{array}{l}\text { EGFR } \\
\text { T790M }\end{array}$ & 11 & - & 66 \\
\hline 39 & III & 272 & Second line & Nivolumab & Docetaxel & PD-I & 3.5 & 9.2 & 20 \\
\hline 37 & III & 582 & Second line & Nivolumab & Docetaxel & PD-I & 2.3 & 12.2 & 19 \\
\hline 13 & I & 495 & Second line & Pembrolizumab & None & PD-I & 3.7 & 12.0 & 19.4 \\
\hline 42 & $\| / / I I$ & $\mathrm{I}, 034$ & Second line & Pembrolizumab & Docetaxel & PD-I & 3.9 & 10.4 & 18 \\
\hline 43 & III & 305 & First line & Pembrolizumab & $\begin{array}{l}\text { Cisplatin (or carboplatin) + } \\
\text { pemetrexed (or paclitaxel; } \\
\text { or gemcitabine) }\end{array}$ & PD-I & 10.3 & - & 44.8 \\
\hline 44 & II & 287 & Second line & Atezolizumab & Docetaxel & PD-LI & 2.7 & 12.6 & 14.3 \\
\hline 45 & III & 850 & Second line & Atezolizumab & Docetaxel & PD-LI & 2.8 & 13.8 & 13.6 \\
\hline
\end{tabular}

Abbreviations: ALK, anaplastic lymphoma kinase; EGFR, epidermal growth factor receptor; FDA, US Food and Drug Administration; NSCLC, non-small cell lung cancer; OS, overall survival; ORR, objective response rate; PD-I, programmed cell death I; PFS, progression-free survival; VEGF, vascular endothelial growth factor; VEGFR, VEGF receptor.

and 8 each 3-week cycle. Necitumumab received its FDA approval based on a randomized, open-label, Phase III study of 1,093 patients with stage IV squamous NSCLC who had not received previous chemotherapy for their disease. ${ }^{8}$ The addition of necitumumab to chemotherapy (gemcitabine and cisplatin) versus chemotherapy alone showed a significant improvement in OS. The median OS was 11.5 months for patients treated with chemotherapy and necitumumab versus 9.9 months for patients treated with chemotherapy alone (HR $=0.84,95 \%$ CI: $0.74-0.96, P=0.01) .{ }^{8}$ A significant improvement in PFS was also seen in patients receiving necitumumab and chemotherapy (5.7 months) versus chemotherapy alone (5.5 months, $\mathrm{HR}=0.85,95 \%$ CI: $0.74-0.98$, $P=0.02){ }^{8}$ The most common adverse events experienced with the addition of necitumumab were rash and hypomagnesemia. ${ }^{8}$ These improvements in OS and PFS are not as clinically significant as the EGFR-targeted TKIs, and consequently, necitumumab is not as widely utilized.

\section{TKIs targeting EGFR}

\section{Erlotinib}

Erlotinib (Tarceva ${ }^{\circledR}$; Genentech, South San Francisco, CA, USA), originally approved by the FDA in 2004, is a firstgeneration TKI that binds reversibly to EGFR. ${ }^{9}$ It is currently approved for the first-line treatment of patients with metastatic NSCLC whose tumors have EGFR exon 19 deletions or exon 21 substitution mutations. The FDA-approved dose is $150 \mathrm{mg}$ orally once daily taken on an empty stomach. Erlotinib received its approvals based on three sentinel trials. The first trial was an international, Phase III, randomized, doubleblind, placebo-controlled study of 731 patients with stage IIIB or IV NSCLC who have failed first-line or second-line 
chemotherapy. Erlotinib showed a significant improvement in OS versus placebo. ${ }^{10}$ The median OS was 4.7 months in the placebo group versus 6.7 months in the erlotinib group (HR $=0.70,95 \%$ CI: $0.58-0.85, P<0.001)$. A significant improvement in PFS was also seen in patients receiving erlotinib (2.2 months) versus placebo ( 1.8 months, $\mathrm{HR}=0.61,95 \%$ CI: $0.51-0.74, P<0.001)$. Patients receiving erlotinib experienced more rash, anorexia, stomatitis, diarrhea, ocular toxicity, and infections compared to patients receiving placebo. ${ }^{10}$ The second trial (Sequential Tarceva in Unresectable NSCLC [SATURN] study) was a multicenter, Phase III, randomized, placebo-controlled study of 889 patients with NSCLC that has not progressed following four cycles of platinum-based chemotherapy. ${ }^{11}$ Erlotinib showed a significantly longer median PFS than placebo (12.3 weeks versus 11.1 weeks, $\mathrm{HR}=0.71$, 95\% CI: 0.62-0.82, $P<0.0001)$. Furthermore, median PFS was significantly longer in EGFR-positive patients receiving erlotinib (12.3 weeks) versus EGFRpositive patients receiving placebo ( 11.1 weeks, $\mathrm{HR}=0.69$, 95\% CI: 0.58-0.82, $P<0.0001)$. The most common adverse effects seen with erlotinib were rash, diarrhea, anorexia, and infections. ${ }^{11}$ The third trial (European patients with advanced EGFR mutation-positive NSCLC [EURTAC] study) was a multicenter, Phase III, randomized, open-label study of 174 patients with stage IIIB (with pleural effusions) or stage IV NSCLC and EGFR mutations (exon 19 deletion or L858R mutation in exon 21) with no history of chemotherapy for metastatic disease. ${ }^{12}$ The addition of erlotinib to chemotherapy (cisplatin or carboplatin plus docetaxel or gemcitabine) resulted in a significant improvement in PFS compared to chemotherapy alone (9.7 versus 5.2 months, $\mathrm{HR}=0.37,95 \%$ CI: $0.25-0.54, P<0.0001)$. The most common adverse effects seen with the addition of erlotinib to chemotherapy were rash and diarrhea. ${ }^{12}$

\section{Gefitinib}

Gefitinib (Iressa ${ }^{\circledR}$; AstraZeneca, Wilmington, DE, USA) is also a first-generation TKI binding reversibly to EGFR. It initially received accelerated approval by the FDA in 2003 as monotherapy for the treatment of patients with advanced NSCLC after the failure of both platinum- and docetaxelbased therapies based on preliminary results showing an ORR of nearly $15 \%$ in a refractory unselected patient population. ${ }^{13}$ Based on the results from the Iressa Survival Evaluation in Lung Cancer (ISEL) trial where gefitinib failed to demonstrate a significant improvement in OS versus placebo, the FDA updated its label in June 2005 restricting use to patients who, in the opinion of their treating physician, are currently benefiting or have previously benefited from gefitinib. The new drug application for the accelerated approval of gefitinib was withdrawn voluntarily in April 2012, but the knowledge of patients with EGFR-mutated NSCLC deriving benefit from gefitinib was mounting. Ultimately, the FDA reapproved gefitinib in 2015 for the first-line treatment of patients with metastatic NSCLC whose tumors have EGFR exon 19 deletions or exon 21 (L858R) substitution mutations. ${ }^{14}$ The FDAapproved dose is $250 \mathrm{mg}$ orally once daily with or without food. Gefitinib received its approval based on two studies. The first study, the Iressa Follow-Up Measure Study (IFUM) study, was a Phase IV, open-label, single-arm study of 106 patients with stage IIIA/B/IV, EGFR-positive NSCLC. ${ }^{15}$ The ORR, the study's primary endpoint, was $69.8 \%$ (95\% CI: 60.5-77.7). Secondary endpoints included disease control rate (DCR) (90.6\%; 95\% CI: 83.5-94.8), median PFS (9.7 months; 95\% CI: 8.5-11.0), and median OS (19.2 months; 95\% CI: 17.0-not reached). The most common adverse events experienced were rash and diarrhea. ${ }^{15}$ The second study was an exploratory analysis of a randomized, Phase III, multicenter, open-label trial of 228 patients of chemotherapy-naive advanced NSCLC with sensitive EGFR mutations (NEJ002 study). ${ }^{16}$ The updated median PFS showed a significant improvement with gefitinib (10.8 months) versus carboplatin/ paclitaxel (5.4 months, HR $=0.32$, 95\% CI: 0.24-0.44, $P<0.001)$. The updated median OS showed no difference between gefitinib (27.7 months) and carboplatin/paclitaxel (26.6 months, HR $=0.89,95 \%$ CI: $0.63-1.24, P=0.483$ ). Rash and diarrhea were commonly seen with gefitinib.

\section{Afatanib}

Afatanib (Gilotrif ${ }^{\circledR}$; Boehringer Ingelheim, Ridgefield, CT, USA) is a second-generation TKI that binds irreversibly to wild-type EGFR and mutated EGFR, with the latter being inhibited at a lower threshold than the wild-type form. It was approved by the FDA in 2013 and is indicated for the first-line treatment of patients with metastatic NSCLC whose tumors have EGFR exon 19 deletions or exon 21 (L858R) substitution mutations. ${ }^{17}$ The FDA-approved dose is $40 \mathrm{mg}$ orally once daily on an empty stomach. Afatanib received its approval based on a Phase III, randomized, open-label study of 364 treatment-naive patients with stage IIIB or IV, EGFR-positive NSCLC. ${ }^{18}$ Afatanib had a significantly longer median PFS (11.0 months) versus gemcitabine/cisplatin (5.6 months, HR $=0.28,95 \%$ CI: $0.20-0.39, P<0.0001$ ). Diarrhea, rash, stomatitis/mucositis, paronychia, epistaxis, pruritus, decreased appetite, and fatigue were seen most often with afatanib. 


\section{Osimertinib}

Osimertinib (Tagrisso ${ }^{\circledR}$; AstraZeneca) is a third-generation TKI originally approved by the FDA in 2015 and is indicated for the treatment of patients with metastatic EGFR T790M mutation-positive NSCLC who have progressed on or after EGFR TKI therapy. ${ }^{19}$ The FDA-approved dose is $80 \mathrm{mg}$ orally once daily with or without food. The significance of this approval is that it overcomes the EGFR T790M resistance mutation, a substitution of threonine with methionine at amino acid position 790 on EGFR, which accounts for $60 \%$ of acquired resistance to EGFR TKIs. ${ }^{20}$ Original approval came from two multicenter, single-arm, open-label, Phase II trials consisting of T790M-positive advanced NSCLC patients who progressed on EGFR TKI therapy. ${ }^{19}$ Recently updated data from a preplanned pooled analysis of these two Phase II studies, consisting of 411 patients, showed an ORR of $66 \%$ (95\% CI: $61-71)$, a median duration of response of 12.5 months (95\% CI: 11.1 months to-not reached), and a median PFS of 11.0 months (95\% CI: 9.6-12.4). ${ }^{21}$ Common adverse events with osimertinib were rash and diarrhea. Although osimertinib was developed to overcome acquired resistance to first- and second-generation TKIs, it is increasingly evident that acquired resistance to even the third-generation TKI is possible through mechanisms such as the $\mathrm{C} 797 \mathrm{~S}$ mutation in exon 20 that impairs covalent binding of the drug to EGFR.

\section{ALK-targeted therapies:TKIs targeting ALK}

ALK is a tyrosine kinase that is typically not expressed in normal adult lung tissue and is therefore not normally active. However, $~ 5 \%$ of patients with NSCLC have tumors that harbor ALK mutations. The most common genetic variant is a rearrangement and fusion of ALK with echinoderm microtubule-associated protein-like 4 (EML4), resulting in a constitutively active tyrosine kinase. This leads to increased mitosis, survival, and antiapoptotic signals to the nucleus of the cells, thereby driving oncogenesis. ${ }^{22}$ Interestingly, EML4-ALK mutations are most common in patients who have either smoked lightly or never smoked and are mutually exclusive of the EGFR-sensitizing mutations in TKI-naive patients. ${ }^{22,23}$ Currently, there are three FDA-approved ALK-targeted TKIs. In general, they have shown improved ORR and PFS compared to chemotherapy, but like the EGFR-targeted TKIs, acquired resistance can arise through ALK mutations (L1196M, F1174L, and G1202R) and activation of other oncogenic pathways. ${ }^{24}$

\section{Crizotinib}

Crizotinib (Xalkori ${ }^{\circledR}$; Pfizer, New York, NY, USA) is a multikinase inhibitor and binds ALK, hepatocyte growth factor receptor (HGFR; c-Met), ROS proto-oncogene 1 (ROS1), and recepteur d'origine nantais (RON). It was the first TKI approved for ALK-positive advanced or metastatic NSCLC..$^{25}$ The FDAapproved dose is $250 \mathrm{mg}$ orally twice daily with or without food. Crizotinib received its approval based on two clinical trials. ${ }^{26}$ The first trial was a multicenter, single-arm, Phase I study consisting of 116 evaluable patients with ALK-positive advanced NSCLC. The ORR was $61 \%$ (95\% CI: 52-70) with two complete responses and 69 partial responses. The median duration of response (DOR) was 48.1 weeks (range: 4.176.6 weeks). The second trial was a multicenter, single-arm, Phase II study consisting of 135 evaluable patients with ALKpositive advanced NSCLC who had progression after at least one line of chemotherapy. The ORR was 50\% (95\% CI: 42-59) with one complete response and 67 partial responses. The median DOR was 33.1 weeks. The efficacy of crizotinib was later confirmed in two randomized, Phase III trials, 347 patients in PROFILE 1007 (crizotinib versus docetaxel or pemetrexed chemotherapy in the second-line setting $)^{27}$ and 343 patients in PROFILE 1014 (crizotinib versus combination of platinum and pemetrexed chemotherapy in the first-line setting) ${ }^{28} \mathrm{In}$ the first-line setting, crizotinib demonstrated superior ORR (74\% versus $45 \%$ ) and PFS (10.9 versus 7.0 months). Similar results were also reported in the second-line setting with an improved ORR (65\% versus $20 \%$ ) and PFS (7.7 versus 3.0 months). Crizotinib was also associated with better patient quality of life compared to cytotoxic chemotherapy. Visual disorders, nausea, vomiting, diarrhea, constipation, edema, fatigue, decreased appetite, dizziness, cough, and dyspnea were commonly seen with crizotinib. Crizotinib is currently the first-line standard of care for advanced ALK-positive NSCLC patients.

More recently, the anticancer efficacy of crizotinib was investigated in metastatic NSCLC patients expressing genetic aberrations in ROS1, typically $1 \%-2 \%$ of TKI-naive NSCLC patients. In this Phase I study of 50 patients with ROS1positive tumors treated with crizotinib at the standard dose, the ORR was $72 \%$ with three complete responses and 33 partial responses, with similar tolerability as ALK-positive NSCLC patients..$^{29}$ Based on these data, crizotinib was also approved for use in this second molecular subgroup of NSCLC.

\section{Ceritinib}

Ceritinib (Zykadia ${ }^{\circledR}$; Novartis, East Hanover, NJ, USA) is the second TKI approved for patients with ALK-positive 
metastatic NSCLC who have progressed on or are intolerant to crizotinib. ${ }^{2}$ The FDA-approved dose is $750 \mathrm{mg}$ orally once daily on an empty stomach. Ceritinib received its approval based on a multicenter, single-arm, open-label, Phase I study consisting of a subset of 163 patients who had advanced or metastatic NSCLC and failed crizotinib. ${ }^{30}$ The ORR was 56\% (95\% CI: 49-64) with two complete responses and 87 partial responses. The median DOR was 8.3 months $(95 \%$ CI: 6.8-9.7). Adverse events reported were diarrhea, nausea, vomiting, abdominal pain, and fatigue. ${ }^{30}$

\section{Alectinib}

Alectinib (Alecensa ${ }^{\circledR}$; Genentech), originally approved by the FDA in 2015, is a central nervous system (CNS)-active TKI indicated for the treatment of patients with ALK-positive metastatic NSCLC who have progressed on or are intolerant to crizotinib. ${ }^{3}$ The FDA-approved dose is $600 \mathrm{mg}$ orally twice daily with food. Alectinib received its approval based on two small Phase II clinical trials. ${ }^{23,31}$ The first trial was a multicenter, single-arm, Phase II study consisting of 87 patients with ALK-positive stage IIIB-IV NSCLC who had progressed after crizotinib. ${ }^{31}$ The ORR was 52\% (95\% CI: 40-65) with 35 partial responses, and the median DOR was 13.5 months (95\% CI: 6.7 to not reached). ${ }^{31}$ Of the 16 patients who had measurable CNS disease according to RECIST at baseline, 12 patients achieved an intracranial objective response (75\%; 95\% CI: 48-93) with four complete CNS responses and eight partial CNS responses. ${ }^{31}$ The median duration of response was 11.1 months (95\% CI: 5.8-11.1). ${ }^{31} \mathrm{CNS}$ DCR occurred in all 16 patients (100\%; 95\% CI: 79-100). ${ }^{31}$ Of the 52 patients who had measurable or nonmeasurable baseline CNS disease, 21 patients (40\%; 95\% CI: 27-55) achieved an objective response including 13 patients (25\%) who demonstrated a complete response. ${ }^{31}$ The second trial was a global, single-arm, Phase II study consisting of 138 patients with advanced or metastatic NSCLC who had progressed after crizotinib. ${ }^{23}$ The ORR was 50\% (95\% CI: 41-59) with 61 patients achieving a partial response, and the median DOR was 11.2 months (95\% CI: 9.6 to not reached). ${ }^{23}$ Of the 84 patients with CNS metastases at baseline, 23 patients (27\%) achieved a CNS complete response and the DOR was 10.3 months $(95 \% \mathrm{CI}: 7.6-11.2) .{ }^{23}$ Of the 35 patients with measurable CNS disease at baseline, the CNS ORR was 57\% (95\% CI: 39-74) and seven patients achieved a CNS complete response. ${ }^{23}$ Constipation, fatigue, myalgia, and peripheral edema were the adverse effects that patients experienced with alectinib..$^{23,31}$

\section{VEGF- and VEGFR-targeted therapies}

While the EGFR- and ALK-targeted therapies have significantly improved survival rates in eligible NSCLC molecular subtypes, many patients do not have these mutations and are not candidates for these agents. ${ }^{32}$ Since tumor progression is widely believed to require tumor neoangiogenesis, this pathway was also targeted for drug development. ${ }^{33}$ In particular, the vascular endothelial growth factor receptor (VEGFR) pathway plays a critical role in angiogenesis and has been successfully targeted in many solid cancers including lung cancer. ${ }^{33}$ Currently, there are only two angiogenesis inhibitors approved by the FDA for advanced NSCLC, and both are monoclonal antibodies. , $^{5,34}$

\section{Bevacizumab}

Bevacizumab (Avastin ${ }^{\circledR}$; Genentech) was approved in 2006, in combination with carboplatin and paclitaxel, for the first-line treatment of unresectable, locally advanced, recurrent, or metastatic NSCLC. ${ }^{32}$ Bevacizumab directly binds to vascular endothelial growth factor A (VEGFA) to prevent the interaction of VEGF with its receptors on the surface of cells. The FDA-approved dose is $15 \mathrm{mg} / \mathrm{kg}$ intravenously every 3 weeks in combination with carboplatin and paclitaxel. ${ }^{5}$ Bevacizumab received its FDA approval based on a randomized, open-label, Phase III study of 878 patients with recurrent or advanced NSCLC (stage IIIB or IV). ${ }^{5}$ The addition of bevacizumab to chemotherapy (carboplatin and paclitaxel) versus chemotherapy alone showed a significant improvement in OS. The median OS was 12.3 months with chemotherapy and bevacizumab versus 10.3 months for patients treated with chemotherapy alone $(\mathrm{HR}=0.79,95 \%$ CI: $0.67-0.92, P=0.003)$. A significant improvement in PFS was also seen in patients receiving bevacizumab and chemotherapy (6.2 months) versus chemotherapy alone (4.5 months, $\mathrm{HR}=0.66$, 95\% CI: 0.57-0.77, $P<0.001)$. Bleeding events were greater in those receiving bevacizumab and chemotherapy $(4.4 \%)$ versus chemotherapy alone $(0.7 \% ; P<0.001)$. Furthermore, patients receiving bevacizumab and chemotherapy experienced more neutropenia, thrombocytopenia, hyponatremia, hypertension, proteinuria, headaches, and rash compared to patients receiving chemotherapy alone. ${ }^{5}$

\section{Ramucirumab}

Ramucirumab (Cyramza ${ }^{\circledR}$; Eli Lilly and Company) directly binds the VEGFR-2 receptor and was approved in 2014, in combination with docetaxel for the treatment of patients 
with metastatic NSCLC with disease progression on or after platinum-based chemotherapy. ${ }^{32}$ This was based on a Phase III trial (REVEL) comparing ramucirumab with docetaxel versus docetaxel monotherapy in 1,253 patients showing a significant improvement in ORR (23\% versus $14 \%$, $P<0.001$ ), PFS (4.5 versus 3.0 months, $P<0.001$ ), and OS (10.5 versus 9.1 months, $P=0.024) .{ }^{34}$ Ramucirumab is administered at $10 \mathrm{mg} / \mathrm{kg}$ with docetaxel $75 \mathrm{mg} / \mathrm{kg}$ every 3 weeks, with the most common adverse effects being myelosuppression, mucositis, and fatigue/asthenia. ${ }^{34}$

\section{Immune checkpoint inhibitors}

It is increasingly recognized that the immune system plays critical roles in the development and progression of cancer. It is now well established that tumors have numerous mechanisms of suppressing the antitumor immune response, including production of inhibitory cytokines, recruitment of immunosuppressive immune cells, and upregulation of coinhibitory receptors known as immune checkpoints. ${ }^{35}$ Under normal physiological conditions, the immune checkpoints serve to inhibit immune responses against self-antigens, thereby preventing unwanted autoimmunity. However, these inhibitory pathways are upregulated in many cancers and immune checkpoints play critical roles in cancer-associated immune suppression and immune evasion. ${ }^{36}$ Currently, the most clinically successful of these approaches are the immune checkpoint inhibitors targeting the programmed cell death 1 (PD-1) and cytotoxic T-lymphocyteassociated molecule 4 (CTLA-4) pathways. ${ }^{37}$

\section{PD- I/PD-LI-targeted therapies}

PD-1 is a cell surface receptor that is found on numerous immune cells such as T cells, B cells, and natural killer cells. ${ }^{36,37}$ Its main function is to limit T-cell activity during an infection or an inflammatory response. Cancer cells can upregulate this receptor and anergize $\mathrm{T}$ cells that come into contact with the tumor. In addition, regulatory $\mathrm{T}$ cells in tumors are thought to further suppress immune function within the tumor microenvironment. Blockade of the PD-1 pathway is thought to increase antitumor immune function in $\mathrm{T}$ cells, enhance natural killer-cell activity, and enhance antibody production in PD-1 + B cells. ${ }^{36,37}$ Currently, there are three PD-1/PD-L1 inhibitors available, nivolumab and pembrolizumab which target PD-1 receptors, and atezolizumab which targets PD-L1, a ligand for the PD-1 receptor. Both nivolumab and pembrolizumab have been shown to have a significantly increased PFS and OS compared to conventional chemotherapy and are approved for the second-line treatment of NSCLC. However, pembrolizumab is also approved for the first-line treatment of NSCLC, although it requires PD-L1 testing in patients whereas nivolumab does not. ${ }^{38,39}$

\section{Nivolumab}

Nivolumab (Opdivo ${ }^{\circledR}$; Bristol-Myers Squibb, Princeton, NJ, USA), a PD-1 receptor inhibitor, is the first immune checkpoint inhibitor approved for metastatic NSCLC with progression on or after platinum-based chemotherapy. ${ }^{6}$ The FDA-approved dose is $3 \mathrm{mg} / \mathrm{kg}$ intravenously every 2 weeks. Two Phase III trials led to nivolumab's approval. The first trial was the CheckMate-017 trial, a randomized, open-label, international, Phase III study consisting of 272 patients with stage IIIB or IV squamous-cell NSCLC who had disease recurrence after one prior platinum-containing regimen. ${ }^{39}$ Nivolumab showed significant improvement in OS versus docetaxel. The median OS was 9.2 months $(95 \%$ CI: 7.3-13.3) with nivolumab versus 6.0 months $(95 \% \mathrm{CI}$ : 5.1-7.3) with docetaxel $(\mathrm{HR}=0.59,95 \% \mathrm{CI}: 0.44-0.79$, $P<0.001)$. The ORR favored nivolumab $(20 \%)$ over docetaxel $(9 \%, P=0.008)$. The median PFS was 3.5 months with nivolumab versus 2.8 months with docetaxel $(\mathrm{HR}=0.62,95 \%$ CI: $0.47-0.81, P<0.001)$. The most common adverse events seen with nivolumab were fatigue, decreased appetite, and asthenia versus docetaxel patients experiencing neutropenia, fatigue, alopecia, and nausea more often. Subgroup analyses showed that patients with at least 5\% PD-L1 expression had an increase in OS with nivolumab over docetaxel. The second trial, the CheckMate-057 trial, was a randomized, open-label, international, Phase III study consisting of 582 patients with stage IIIB, IV, or recurrent nonsquamous NSCLC after radiation therapy or surgical resection who also had disease progression or recurrence during or after one prior platinum-based doublet regimen. ${ }^{38}$ Nivolumab had a significant improvement in OS over docetaxel. The median OS was 12.2 months (95\% CI: 9.7-15.0) with nivolumab versus 9.4 months (95\% CI: 8.1-10.7) with docetaxel (HR $=0.73$, 95\% CI: $0.59-0.89, P=0.002)$. The ORR favored nivolumab (19\%; 95\% CI: 15-24) over docetaxel (12\%; 95\% CI: 9-17, $P=0.02$ ). The median PFS was 2.3 months in the nivolumab group versus 4.2 months in the docetaxel group $(\mathrm{HR}=0.92,95 \% \mathrm{CI}: 0.77-1.11, P=0.39)$. PD-L1 expression was also monitored, and in patients with at least $5 \%$ expression, there was an increase in OS with nivolumab over docetaxel. The adverse effects most frequently reported with nivolumab were fatigue, nausea, decreased appetite, and asthenia versus docetaxel patients experiencing neutropenia, fatigue, nausea, and alopecia. As of August 2016, 
results from the CheckMate-026 trial, investigating the use of nivolumab as monotherapy in patients with previously untreated advanced NSCLC whose tumors expressed PD-L1 of at least 5\%, did not meet its primary endpoint of PFS as compared to investigator's choice chemotherapy (gemcitabine/cisplatin, gemcitabine/carboplatin, or paclitaxel carboplatin in squamous NSCLC and pemetrexed/cisplatin or pemetrexed/carboplatin in non-squamous NSCLC). ${ }^{40}$ However, the impact on OS remains to be determined.

\section{Pembrolizumab}

Pembrolizumab (Keytruda ${ }^{\circledR}$; Merck, Whitehouse Station, NJ, USA), another PD-1 receptor inhibitor, is the second immune checkpoint inhibitor granted accelerated approval from the FDA for the treatment of metastatic NSCLC whose tumors express PD-L1 as determined by an FDA-approved test and who have disease progression on or after platinum-containing therapy. ${ }^{13}$ The FDA-approved dose is $2 \mathrm{mg} / \mathrm{kg}$ intravenously every 3 weeks. Approval was based on the KEYNOTE-001 trial, an international, Phase I trial of 495 patients with advanced or metastatic NSCLC receiving $2 \mathrm{mg} / \mathrm{kg}$ every 3 weeks, $10 \mathrm{mg} / \mathrm{kg}$ every 3 weeks, or $10 \mathrm{mg} / \mathrm{kg}$ every 2 weeks of pembrolizumab intravenously. ${ }^{41}$ Patients were stratified into a training group (182 patients) or a validation group (313 patients) that identified a PD-L1 expression level of 50\%. With regard to all patients, the ORR was $19.4 \%$ (95\% CI: 16.0-23.2), the median duration of response was 12.5 months (range: 1.0-23.3 months), the median PFS was 3.7 months (95\% CI: 2.9-4.1), and the median OS was 12.0 months (95\% CI: 9.3-14.7). In patients with PD-L1 expression of at least 50\%, the ORR was $45.2 \%$ (95\% CI: 33.5-57.3), the median duration of response was 12.5 months (range: 2.1-23.3 months), the median PFS was 6.3 months (95\% CI: 2.9-12.5), and the median OS was not reached $(95 \%$ CI: 13.7 to not reached). The common adverse events were fatigue, pruritus, and decreased appetite with no difference according to dose or schedule. Notably, pembrolizumab was initially only indicated in advanced NSCLC patients with high PD-L1 expression ( $>50 \%$ ). However, updated results of KEYNOTE-001 showed that in the training group, 79 patients with PD-L1 expression of at least $1 \%$ had a median OS of 22.1 months (95\% CI: 16.7-27.2). ${ }^{42}$ Furthermore, in the validation group, 306 previously treated patients with PD-L1 expression of at least $1 \%$ had a median OS of 11.3 months (95\% CI: 8.3-14.0). ${ }^{42}$

Subsequently, pembrolizumab received approval to expand its second-line indication to all metastatic NSCLC patients with tumor PD-L1 expression of at least $1 \%$ based on the results of the KEYNOTE-010, a randomized, open-label, international, Phase II/III study of 1,034 patients with previously treated, PD-L1-positive, advanced NSCLC treated with pembrolizumab $2 \mathrm{mg} / \mathrm{kg}$ and $10 \mathrm{mg} / \mathrm{kg}$, or docetaxel. ${ }^{43}$ The median OS was 10.4 months with pembrolizumab $2 \mathrm{mg} / \mathrm{kg}$, 12.7 months with pembrolizumab $10 \mathrm{mg} / \mathrm{kg}$, and 8.5 months with docetaxel. The OS was significantly longer with pembrolizumab $2 \mathrm{mg} / \mathrm{kg}$ versus docetaxel ( $\mathrm{HR}=0.71,95 \%$ CI: $0.58-0.88, P=0.0008)$ and with pembrolizumab $10 \mathrm{mg} / \mathrm{kg}$ versus docetaxel (HR $=0.61,95 \% \mathrm{CI}: 0.49-0.75, P<0.0001)$. Among patients with tumors expressing at least 50\% PD-L1, the median OS was significantly longer with pembrolizumab $2 \mathrm{mg} / \mathrm{kg}$ than with docetaxel (14.9 versus 8.2 months, $\mathrm{HR}=0.54,95 \% \mathrm{CI}: 0.38-0.77, P=0.0002)$ and with pembrolizumab $10 \mathrm{mg} / \mathrm{kg}$ than with docetaxel (17.3 versus 8.2 months, $\mathrm{HR}=0.50,95 \% \mathrm{CI}: 0.36-0.70, P<0.0001)$.

Importantly, pembrolizumab is currently the only immune checkpoint inhibitor approved for the first-line treatment of advanced NSCLC in eligible molecular subtypes (PD-L1 high, EGFR negative, and ALK negative). This was based on KEYNOTE-024, a randomized open-label trial in 305 previously untreated metastatic NSCLC patients with tumor PD-L1 expression of at least $50 \%$ treated with pembrolizumab (200 mg every 3 weeks) or platinum-based chemotherapy. ${ }^{44}$ Pembrolizumab demonstrated a significant improvement in PFS ( $\mathrm{HR}=0.50 ; 95 \% \mathrm{CI}$ : 0.37-0.68; $P<0.001)$ with a median PFS of 10.3 versus 6.0 months for those receiving platinum-based chemotherapy. A prespecified interim analysis also showed a significant improvement in OS (HR $=0.60 ; 95 \%$ CI: $0.41-0.89 ; P<0.005)$.

\section{Atezolizumab}

Atezolizumab (Tecentriq ${ }^{\circledR}$; Genentech), a monoclonal antibody targeting the PD-L1 ligand, is approved for the treatment of metastatic NSCLC after the failure of platinumcontaining chemotherapy treatment. This was based on two randomized, open-label clinical trials (OAK and POPLAR) in a total of 1,137 patients with NSCLC, comparing safety and efficacy of atezolizumab (1,200 mg every 3 weeks) with docetaxel. ${ }^{45,46}$ Treatment with atezolizumab significantly improved OS: the median OS was 13.8 months in OAK (95\% CI: $11.8-15.7)$ compared to 9.6 months (95\% CI: 8.6-11.2) in the docetaxel $\operatorname{arm}(\mathrm{HR}=0.74 ; 95 \% \mathrm{CI}: 0.63-0.87 ; P=0.0004)$. The median OS in POPLAR was 12.6 months $(95 \% \mathrm{CI}$ : 9.7-16.0) and 9.7 months (95\% CI: 8.6-12.0) (HR =0.69; 95\% CI: 0.52-0.92) for the atezolizumab and docetaxel arms, respectively. The most common adverse events in patients treated with atezolizumab were fatigue, decreased 
appetite, dyspnea, cough, nausea, musculoskeletal pain, and constipation. The most common serious adverse events were dyspnea, pneumonia, hypoxia, hyponatremia, fatigue, anemia, musculoskeletal pain, aspartate transaminase increase, alanine transaminase increase, dysphagia, and arthralgia. As the other immune checkpoint inhibitors, patients receiving atezolizumab also experienced immune-related adverse events, including pneumonitis, hepatitis, colitis, and thyroid disease.

\section{CTLA-4-targeted therapies}

The CTLA-4 receptors are expressed on antigen-presenting cells as well as tumor cells and are overexpressed in many cancers. Activation of this receptor leads to inhibition of naive and memory $\mathrm{T}$-cell functions, contributing to the development of cancer antigen tolerance in T cells. ${ }^{36}$ Currently, ipilimumab is the only approved anticancer agent targeting CTLA-4 and acts by preventing the receptor on antigen presenting cells from interacting with CD80/CD86 on T cells, which allows CD80/CD86 to interact with costimulatory receptors, thereby promoting immune activation. ${ }^{47}$

\section{Ipilimumab}

Ipilimumab (Yervoy ${ }^{\circledR}$; Bristol-Myers Squibb), a monoclonal antibody targeting the CTLA-4 immune checkpoint, is approved for the treatment of advanced melanoma patients as monotherapy or in combination with nivolumab, in the second-line setting. Ipilimumab in combination with nivolumab is being investigated in a Phase III trial for the first-line treatment of NSCLC in the CheckMate-227, based on promising results from an earlier Phase I trial, CheckMate-012. ${ }^{48}$ In this study, patients with advanced NSCLC were randomized to receive nivolumab alone ( $3 \mathrm{mg} / \mathrm{kg}$ given every 2 weeks), nivolumab and ipilimumab given every 12 weeks, or nivolumab and ipilimumab given every 6 weeks. The overall response rates were $23 \%, 47 \%$, and $39 \%$, respectively, with similar rates of treatment discontinuation of $10 \%$ across all treatment groups, suggesting that tolerability was similar between monotherapy and combination treatments. ${ }^{47}$

\section{Emerging targeted therapies Vemurafenib}

Vemurafenib (Zelboraf ${ }^{\circledR}$; Genentech), approved for patients with unresectable or metastatic melanoma with BRAF V600E mutation, is a kinase inhibitor that has shown activity against NSCLC but is currently not approved in NSCLC. ${ }^{23,49}$ In a histology-independent Phase II study with seven cancer cohorts that were all BRAF V600 mutation positive,
20 patients were enrolled in the NSCLC cohort. ${ }^{49}$ The ORR was 42\% (95\% CI: 20-67) with eight partial responses. The median PFS was 7.3 months (95\% CI: 3.5-10.8), the 12-month rate of PFS was 23\% (95\% CI: 6-46), and the preliminary $12-$ month OS was $66 \%$ (95\% CI: 36-85). The median OS had not yet been reached. Rash and fatigue were commonly experienced by patients.

\section{Dabrafenib}

Dabrafenib (Tafinlar ${ }^{\circledR}$; Novartis) is a kinase inhibitor approved for patients with unresectable or metastatic melanoma with BRAF V600E mutations that has shown activity against NSCLC but not approved for NSCLC. ${ }^{37,38,50}$ In a multicenter, nonrandomized, open-label, Phase II study, 84 patients with previously treated (at least one line of chemotherapy) and untreated stage IV metastatic BRAF (V600E)-positive NSCLC were treated with oral dabrafenib $150 \mathrm{mg}$ twice daily. ${ }^{50}$ Patients with EGFR mutations or ALK rearrangements were eligible as long as they received a prior EGFR or ALK inhibitor, respectively. Four of the six untreated patients receiving first-line treatment with dabrafenib had achieved a partial response. The ORR for the 78 patients receiving dabrafenib as a second-line or later treatment occurred in 26 patients (33\%; 95\% CI: $23-45)$ with all 26 patients achieving a partial response. The median DOR was 9.6 months (95\% CI: 5.4-15.2) and the median PFS was 5.5 months (95\% CI: 3.4-7.3). Another single-arm, two-stage, Phase II study utilized a combination of dabrafenib and trametinib, an MAPK/ERK kinase (MEK) inhibitor, in 24 evaluable patients with advanced BRAF (V600E)-positive NSCLC who failed at least one line of chemotherapy. ${ }^{38}$ The ORR was $63 \%$ (95\% CI: 41-81) with 15 partial responses observed in 6 weeks. Common adverse effects reported with dabrafenib were pyrexia, diarrhea, nausea, vomiting, decreased appetite, asthenia, cough peripheral edema, fatigue, and rash.

\section{Trametinib}

Trametinib (Mekinist ${ }^{\circledR}$; Novartis), originally approved by the FDA in 2013 in combination with dabrafenib for the treatment of patients with unresectable or metastatic melanoma with BRAF V600E or V600K mutations, is an MEK inhibitor that has shown activity against NSCLC but not currently approved for this indication. ${ }^{38,39,51}$ As previously mentioned, trametinib has shown activity in combination with dabrafenib in NSCLC, but it has also proven to have activity as monotherapy. ${ }^{38,51}$ In an open-label, multicenter, randomized, Phase II study, 129 patients with KRAS-mutant stage IV NSCLC were randomly assigned 2:1 to trametinib or docetaxel. ${ }^{51}$ The median PFS was 12 weeks with trametinib 
versus 11 weeks in the docetaxel arm $(\mathrm{HR}=1.14,95 \%$ CI: $0.75-1.75, P=0.5197)$. The median OS was 8 months in the trametinib arm and not reached in the docetaxel arm (HR $=0.97,95 \% \mathrm{CI}: 0.52-1.83, P=0.934)$. There were $10(12 \%)$ partial responses in the trametinib arm and five $(12 \%)$ partial responses in the docetaxel arm $(P=1.0000)$. Although the results were similar, the clinical significance cannot be fully elucidated due to the underwhelming results and small sample size. Rash, diarrhea, nausea, vomiting, and fatigue were the adverse events reported with trametinib.

\section{Cabozantinib}

Cabozantinib (Cabometyx ${ }^{\circledR}$; Exelixis, South San Francisco, CA, USA) is a multi-TKI approved for progressive metastatic medullary thyroid cancer that has shown activity against NSCLC but is not approved for NSCLC currently. ${ }^{39,40}$ In a single-center, open-label, Phase II study, 20 patients with rearranged during transfection stage IV NSCLC were administered cabozantinib $60 \mathrm{mg}$ orally daily. ${ }^{39}$ The ORR was $28 \%$ (95\% CI: 10-53) with five partial responses. The median PFS was 7 months (95\% CI: 3 to not reached), and the median OS was not reached. Patients commonly experienced fatigue, diarrhea, palmar-plantar erythrodysesthesia, transaminitis, and thrombocytopenia.

\section{Indoximod}

Indoximod (NLG-8189; NewLink Genetics, Ames, IA, USA), an indoleamine 2,3-dioxygenase (IDO) inhibitor, is an immune checkpoint inhibitor with activity in NSCLC. ${ }^{52}$ IDO is involved in increasing the number of immunosuppressive T-regulatory cells. Thus, an inhibitor of this pathway can reverse this effect. The only reported in-man Phase I trial studied the combination of docetaxel and indoximod in 29 patients with metastatic solid tumors. ${ }^{52}$ Of these patients, 10 patients had NSCLC, of whom two of them showed a reduction in tumor size ( $56.5 \%$ and $8.2 \%$ ). Common adverse events experienced with the combination of docetaxel and indoximod included anemia, fatigue, and hyperglycemia.

\section{The question of KRAS mutations}

An area of much needed research in NSCLC is KRASmutated tumors. Currently, there are no FDA-approved therapies for such mutations. However, the BATTLE-2 trial (a biomarker-integrated targeted therapy study in previously treated patients with advanced non-small cell lung cancer) is poised to address this issue..$^{53}$ This was a randomized, Phase II, multicenter, open-label study that included 200 patients with advanced NSCLC (excluding sensitizing EGFR mutations and ALK gene fusions) refractory to more than one prior therapy who were stratified based on KRAS mutation status. Patients were stratified to receive erlotinib (arm 1), erlotinib and MK-2206 (arm 2), MK-2206 and AZD6244 (arm 3), or sorafenib (arm 4). MK-2206 is an allosteric protein kinase B inhibitor, while AZD6244 is an MEK inhibitor, two agents with promise against KRAS-positive cancers. Twenty-seven percent of the study participants were KRAS mutant positive. The primary end-point was 8-week DCR. Overall, the DCR was $48 \%$ with $32 \%$ in arm $1,50 \%$ in arm $2,53 \%$ in arm 3 , and $46 \%$ in arm 4 . The DCR in KRAS mutant positive patients was $20 \%$ in arm $1,25 \%$ in arm $2,62 \%$ in arm 3 , and $44 \%$ in arm 4. In KRAS wild-type patients, the DCR was $36 \%$ in arm $1,57 \%$ in arm 2, 49\% in arm 3, and $47 \%$ in arm 4. Patients with KRAS mutant positive tumors experienced a statistically longer PFS if treated with therapy that did not contain erlotinib with a median PFS of 1.8 months with arms 1 and 2 combined versus 2.5 months with arms 3 and 4 combined $(\mathrm{HR}=1.95,95 \% \mathrm{CI}: 1.00-3.77, P=0.04)$. However, there was no difference in OS seen among patients who were KRAS mutant positive receiving erlotinib or not. The most common grade $3 / 4$ adverse effect seen in the combined MK-2206/AZD6244 arm was maculopapular rash.

\section{Role and potential impact of nivolumab}

The World Health Organization estimated that there were 1.53 million new cases of NSCLC in 2012. In addition, 75\% of these patients will progress to have metastatic diseases. ${ }^{54}$ Currently, a category 1 recommendation is in place from the National Comprehensive Cancer Network for nivolumab as second-line therapy for advanced or metastatic NSCLC of either squamous etiology or nonsquamous etiology..$^{15}$ Nivolumab will have a significant impact on this population of patients because of its clinical efficacy and its economic costs. Nivolumab has a yearly cost of $\sim \$ 64,860,{ }^{55}$ which, according to Walstra, was not cost-effective compared to docetaxel in all patients treated with NSCLC in the Swiss Health Care System (\$177,478/quality-adjusted life year (QALY) versus $\$ 133,267 /$ QALY, respectively, in US\$). However, when looking at patients with PD-L1 status at both $1 \%$ and $10 \%$, PD-L1 expression produces an incremental cost-effectiveness ratio of $\$ 65,744 / \mathrm{QALY}$ and $\$ 37,860 / \mathrm{QALY}$, respectively, ${ }^{55}$ thus significantly increasing the years gained compared to docetaxel. More research needs to be done to determine its cost-effectiveness in the US health care system.

The results from CheckMate-026 and KEYNOTE-001 beg the question, "Does measuring PD-L1 expression matter to determine if a favorable result will occur?" Currently, the efficacy and economic data suggest that monitoring for 
PD-L1 expression may be worthwhile in determining whether to utilize an immune checkpoint inhibitor in advanced NSCLC. Although nivolumab did not meet its PFS endpoint as first-line therapy in the patients with advanced NSCLC, additional analyses are underway to determine whether raising the $\mathrm{PD}-\mathrm{L} 1$ expression threshold can identify patients more likely to benefit from treatment and other trials are ongoing to determine whether nivolumab combined with other treatments yields clinical benefits in the second-line treatment of NSCLC. This will be further compounded by the introduction of PD-1/PD-L1-directed therapy in the firstline setting in NSCLC. With the approval of pembrolizumab in the first-line setting, we are now seeing an evolution in the role of PD-1-directed therapy. Pembrolizumab is approved under very specific indications in the first-line setting, with the most important being the requirement of $>50 \%$ PD-L1 expression. ${ }^{41}$ It is important to recognize that this may only represent a small proportion of patients who express this level of PD-L1 ( $25 \%$ of those screened $).{ }^{41}$ In contrast, the original nivolumab trials did not require expression to utilize nivolumab for treatment. The available evidence in lung cancer suggests that PD-L1 expression is not only a predictor of response, but it will also be a requirement for future drug approval in order to compete with pembrolizumab's place in therapy.

\section{Conclusion}

Trials are underway evaluating the combination of nivolumab and ipilimumab, or platinum chemotherapeutic agents, or erlotinib for treatment-naive advanced NSCLC. ${ }^{48}$ Interestingly, nivolumab is also being evaluated in early-stage NSCLC as adjuvant therapy postsurgery and chemotherapy. ${ }^{56,57}$ Ultimately, the combinations and possibilities with nivolumab for NSCLC are multiple, and the findings from these current as well as future research efforts will clarify the role of nivolumab in the management of NSCLC.

\section{Disclosure}

The authors report no conflicts of interest in this work.

\section{References}

1. Borghaei H, Paz-Ares L, Spigel DR, et al. Nivolumab versus docetaxel in advanced nonsquamous non-small-cell lung cancer. NEngl J Med. 2015; 373(17):1627-1639.

2. Arteaga CL. Overview of epidermal growth factor receptor biology and its role as a therapeutic target in human neoplasia. Semin Oncol. 2002; 29(5 suppl 14):3-9.

3. Matikas A, Mistiotis D, Georgoulias V, Kotaskis A. Current and future approaches in the management of non-small-cell lung cancer patients with resistance to EGFR TKIs. Clin Lung Cancer. 2015;16(4): 252-261.
4. van der Wekken AJ, Saber A, Hiltermann TJ, Kok K, van den Berg A, Groen HJ. Resistance mechanisms after tyrosine kinase inhibitors afatinib and crizotinib in non-small cell lung cancer, a review of the literature. Crit Rev Oncol Hematol. 2016;100:107-116.

5. Sandler A, Gray R, Perry MC, et al. Paclitaxel-carboplatin alone or with bevacizumab for non-small-cell lung cancer. N Engl J Med. 2006; 355(24):2542-2550.

6. Pirker R, Pereira JR, Szczesna A, et al; FLEX Study Team. Cetuximab plus chemotherapy in patients with advanced non-small-cell lung cancer (FLEX): an open-label randomised phase III trial. Lancet. 2009; 373(9674):1525-1531.

7. Higgins JP, Green S, editors. Cochrane Handbook for Systematic Reviews of Interventions: The Cochrane Collaboration. Chichester, UK: John Wiley \& Sons, Ltd; 2011.

8. Thatcher N, Hirsch FR, Luft AV, et al; SQUIRE Investigators. Necitumumab plus gemcitabine and cisplatin versus gemcitabine and cisplatin alone as first-line therapy in patients with stage IV squamous non-small-cell lung cancer (SQUIRE): an open-label, randomised, controlled phase 3 trial. Lancet Oncol. 2015;16(7):763-774.

9. Middleton MR, Dalle S, Claveau J, et al. Real-world treatment practice in patients with advanced melanoma in the era before ipilimumab: results from the IMAGE study. Cancer Med. 2016;5(7): 1436-1443.

10. Shepherd FA, Rodrigues Pereira J, Ciuleanu T, et al; National Cancer Institute of Canada Clinical Trials Group. Erlotinib in previously treated non-small-cell lung cancer. $N$ Engl J Med. 2005;353(2):123-132.

11. Cappuzzo F, Ciuleanu T, Stelmakh L, et al; SATURN investigators. Erlotinib as maintenance treatment in advanced non-small-cell lung cancer: a multicentre, randomised, placebo-controlled phase 3 study. Lancet Oncol. 2010;11(6):521-529.

12. Rosell R, Carcereny E, Gervais R, et al; Spanish Lung Cancer Group in collaboration with Groupe Français de Pneumo-Cancérologie and Associazione Italiana Oncologia Toracica. Erlotinib versus standard chemotherapy as first-line treatment for European patients with advanced EGFR mutation-positive non-small-cell lung cancer (EURTAC): a multicentre, open-label, randomised phase 3 trial. Lancet Oncol. 2012;13(3):239-246.

13. Kazandjian D, Blumenthal GM, Yuan W, He K, Keegan P, Pazdur R. FDA approval of gefitinib for the treatment of patients with metastatic EGFR mutation-positive non-small cell lung cancer. Clin Cancer Res. 2016; 22(6):1307-1312.

14. Puzanov I, Dummer R, Schachter J, et al. Efficacy based on tumor $P D-L 1$ expression in KEYNOTE-002, a randomized comparison of pembrolizumab (pembro; $M K-3475$ ) versus chemotherapy in patients (pts) with ipilimumab-refractory (IPI-R) advanced melanoma (MEL). Poster presented at: 2015 ASCO Annual Meeting; May 29-June 2, 2015; Chicago, IL. Available from: http://meetinglibrary.asco.org/ content/150479-156. Accessed February 14, 2017.

15. Douillard JY, Ostoros G, Cobo M, et al. First-line gefitinib in Caucasian EGFR mutation-positive NSCLC patients: a phase-IV, open-label, single-arm study. Br J Cancer. 2014;110(1):55-62.

16. Inoue A, Kobayashi K, Maemondo M, et al. Updated overall survival results from a randomized phase III trial comparing gefitinib with carboplatinpaclitaxel for chemo-naive non-small cell lung cancer with sensitive EGFR gene mutations (NEJ002). Ann Oncol. 2013;24(1):54-59.

17. Gelao L, Criscitiello C, Esposito A, Goldhirsch A, Curigliano G. Immune checkpoint blockade in cancer treatment: a double-edged sword cross-targeting the host as an "innocent bystander". Toxins. 2014;6(3): 914-933.

18. Wu YL, Zhou C, Hu CP, et al. Afatinib versus cisplatin plus gemcitabine for first-line treatment of Asian patients with advanced non-small-cell lung cancer harbouring EGFR mutations (LUX-Lung 6): an open-label, randomised phase 3 trial. Lancet Oncol. 2014;15(2):213-222.

19. Mantel N, Haenszel W. Statistical aspects of the analysis of data from retrospective studies of disease. J Natl Cancer Inst. 1959;22:719-748.

20. Liao BC, Lin CC, Yang JC. Second and third-generation epidermal growth factor receptor tyrosine kinase inhibitors in advanced nonsmall cell lung cancer. Curr Opin Oncol. 2015;27(2):94-101. 
21. Yang J, Ramalingam SS, Janne PA, Cantarini M, Mitsudomi T. LBA2_PR: Osimertinib (AZD9291) in pre-treated pts with T790Mpositive advanced NSCLC: updated Phase 1 (P1) and pooled Phase 2 (P2) results. J Thorac Oncol. 2016;11(4 suppl):S152-S153.

22. Facchinetti F, Tiseo M, Maio MD, et al. Tackling ALK in non-small cell lung cancer: the role of novel inhibitors. Transl Lung Cancer Res. 2016; 5(3):301-321.

23. Ou SH, Ahn JS, De Petris L, et al. Alectinib in crizotinib-refractory ALK-rearranged non-small-cell lung cancer: a phase II global study. J Clin Oncol. 2016;34(7):661-668.

24. Rothschild S. New treatment options for ALK+ advanced non-small-cell lung cancer: critical appraisal of ceritinib. Ther Clin Risk Manag. 2016; 12:735-741.

25. Johnson DB, Estrada MV, Salgado R, et al. Melanoma-specific MHC-II expression represents a tumour-autonomous phenotype and predicts response to anti-PD-1/PD-L1 therapy. Nat Commun. 2016;7:10582.

26. Malik SM, Maher VE, Bijwaard KE, et al. U.S. Food and Drug Administration approval: crizotinib for treatment of advanced or metastatic non-small cell lung cancer that is anaplastic lymphoma kinase positive. Clin Cancer Res. 2014;20(8):2029-2034.

27. Shaw AT, Kim DW, Nakagawa K, et al. Crizotinib versus chemotherapy in advanced ALK-positive lung cancer. N Engl J Med. 2013;368(25): 2385-2394.

28. Solomon BJ, Mok T, Kim DW, et al; PROFILE 1014 Investigators. First-line crizotinib versus chemotherapy in ALK-positive lung cancer. N Engl J Med. 2014;371(23):2167-2177.

29. Shaw AT, Ou SH, Bang YJ, et al. Crizotinib in ROS1-rearranged nonsmall-cell lung cancer. N Engl J Med. 2014;371(21):1963-1971.

30. Kim DW, Mehra R, Tan DS, et al. Activity and safety of ceritinib in patients with ALK-rearranged non-small-cell lung cancer (ASCEND-1): updated results from the multicentre, open-label, phase 1 trial. Lancet Oncol. 2016;17(4):452-463.

31. Shaw AT, Gandhi L, Gadgeel S, et al; Study Investigators. Alectinib in ALK-positive, crizotinib-resistant, non-small-cell lung cancer: a single-group, multicentre, phase 2 trial. Lancet Oncol. 2016;17(2): 234-242.

32. National Comprehensive Cancer Network. Non-small cell lung cancer (version 4.2017). Available from: https://www.nccn.org/professionals/ physician_gls/pdf/nscl.pdf. Accessed February 14, 2017.

33. Hasani A, Leighl NB. Targeting vascular endothelial growth factor in lung cancer. J Thorac Oncol. 2010;5(12 suppl 6):S484-S486.

34. Garon EB, Ciuleanu TE, Arrieta O, et al. Ramucirumab plus docetaxel versus placebo plus docetaxel for second-line treatment of stage IV non-small-cell lung cancer after disease progression on platinum-based therapy (REVEL): a multicentre, double-blind, randomised phase 3 trial. Lancet. 2014;384(9944):665-673.

35. Drake CG, Jaffee E, Pardoll DM. Mechanisms of immune evasion by tumors. Adv Immunol. 2006;90:51-81.

36. Pardoll D. The blockade of immune checkpoints in cancer immunotherapy. Nav Rev Cancer. 2012;12(4):252-264.

37. La-Beck N, Jean G, Huynh C, Alzghari S, Lowe D. Immune checkpoint inhibitors: new insights and current place in cancer therapy. Pharmacotherapy. 2015;35(10):963-976.

38. Borghaei H, Paz-Ares L, Horn L, et al. Nivolumab versus docetaxel in advanced nonsquamous non-small-cell lung cancer. N Engl J Med. 2015; 373(17):1627-1639.

39. Brahmer J, Reckamp K, Baas P, et al. Nivolumab versus docetaxel in advanced squamous-cell non-cell lung cancer. N Engl J Med. 2015;373: 123-135.

40. Bristol-Meyers Squibb. Bristol-Myers Squibb Announces TopLine Results from CheckMate -026, a Phase 3 Study of Opdivo (nivolumab) in Treatment-Nä̈ve Patients with Advanced Non-Small Cell Lung Cancer. Available from: http://investor.bms.com/investors/ news-and-events/press-releases/press-release-details/2016/BristolMyers-Squibb-Announces-Top-Line-Results-from-CheckMate--026a-Phase-3-Study-of-Opdivo-nivolumab-in-Treatment-Nave-Patientswith-Advanced-Non-Small-Cell-Lung-Cancer/default.aspx. Accessed February 14, 2017.
41. Garon EB, Rizvi NA, Hui R, et al. Pembrolizumab for the treatment of non-small-cell lung cancer. N Engl J Med. 2015;372(21):2018-2028.

42. Hui R, Gandhi L, Costa EC, et al. Long-term OS for patients with advanced NSCLC enrolled in the KEYNOTE-001 study of pembrolizumab (pembro). Poster presented at: 2016 ASCO Annual Meeting; June 3-7, 2016. Chicago, IL, USA. Available from: http://meetinglibrary.asco.org/content/167384-176. Accessed August 10, 2016.

43. Herbst RS, Baas P, Kim DW, et al. Pembrolizumab versus docetaxel for previously treated, PD-L1-positive, advanced non-small-cell lung cancer (KEYNOTE-010): a randomised controlled trial. Lancet. 2016; 387(10027):1540-1550.

44. Reck M, Rodriguez-Abreu D, Robinson AG, et al. Pembrolizumab versus chemotherapy for PD-L1-positive non-small-cell lung cancer. N Engl J Med. 2016;375(19):1823-1833.

45. Fehrenbacher L, Spira A, Ballinger M, et al; POPLAR Study Group. Atezolizumab versus docetaxel for patients with previously treated nonsmall-cell lung cancer (POPLAR): a multicentre, open-label, phase 2 randomised controlled trial. Lancet. 2016;387(10030):1837-1846.

46. Barlesi F, Park K, Ciardiello F, et al. Primary analysis from OAK, a randomized phase III study comparing atezolizumab with docetaxel in 2L/3L NSCLC. Abstract LBA44_PR presented at: European Society for Medical Oncology 2016 Congress, Copenhagen, Denmark, October 7-11, 2016. Available at: http://www.esmo.org/Conferences/ ESMO-2016-Congress/Press-Media/Significant-Survival-Gainswith-Atezolizumab-vs-Docetaxel-for-Non-Small-Cell-Lung-Cancer. Accessed February 14, 2017.

47. Topalian SL, Hodi FS, Brahmer JR, et al. Safety, activity, and immune correlates of anti-PD-1 antibody in cancer. NEngl J Med. 2012;366(26): 2443-2454.

48. Hellman M, Gettinger S, Goldman J, et al. CheckMate 012: Safety and efficacy of first-line (1L) nivolumab (nivo; N) and ipilimumab (ipi; I) in advanced (adv) NSCLC. Paper presented at: ASCO 2016; June 3-7, 2016; Chicago, IL, USA.

49. Hyman DM, Puzanov I, Subbiah V, et al. Vemurafenib in multiple nonmelanoma cancers with BRAF V600 mutations. N Engl JMed. 2015; 373(8):726-736.

50. Planchard D, Kim TM, Mazieres J, et al. Dabrafenib in patients with BRAF(V600E)-positive advanced non-small-cell lung cancer: a singlearm, multicentre, open-label, phase 2 trial. Lancet Oncol. 2016;17(5): 642-650.

51. Blumenschein GR Jr, Smit EF, Planchard D, et al. A randomized phase II study of the MEK1/MEK2 inhibitor trametinib (GSK1120212) compared with docetaxel in KRAS-mutant advanced non-small-cell lung cancer (NSCLC) dagger. Ann Oncol. 2015;26(5):894-901.

52. Soliman HH, Jackson E, Neuger T, et al. A first in man phase I trial of the oral immunomodulator, indoximod, combined with docetaxel in patients with metastatic solid tumors. Oncotarget. 2014;5(18):8136-8146.

53. Papadimitrakopoulou V, Lee JJ, Wistuba II, et al. The BATTLE-2 Study: a biomarker-integrated targeted therapy study in previously treated patients with advanced non-small-cell lung cancer. J Clin Oncol. Epub 2016 Aug 1.

54. WHO. Lung cancer: estimated incidence, mortality and prevalence worldwide in 2012; WHO; 2012. Available from: http://globocan.iarc.fr/old/ FactSheets/cancers/lung-new.asp. Accessed February 14, 2017.

55. Tartari F, Santoni M, Burattini L, Mazzanti P, Onofri A, Berardi R. Economic stability of anti-PD-1 agent nivolumab and pembrolizumab in cancer patients: recent insights and future challenges. Cancer Treat Rev. 2016;48:20-24.

56. Chaft J. Nivolumab after surgery and chemotherapy in treating patients with stage IB-IIIA non-small cell lung cancer (ANVIL); 2016. Available from: https:/clinicaltrials.gov/ct2/show/NCT02595944. NLM identifier: NCT02595944. Accessed October 25, 2016.

57. Squibb B-M. A trial of nivolumab, or nivolumab plus ipilimumab, or nivolumab plus platinum-doublet chemotherapy, compared to platinum doublet chemotherapy in patients with stage IV non-small cell lung cancer (NSCLC) (checkmate 227); 2016. Available from: https:/clinicaltrials.gov/ct2/show/NCT02595944. NLM identifier: NCT02595944. Accessed October 25, 2016. 


\section{Publish your work in this journal}

Therapeutics and Clinical Risk Management is an international, peerreviewed journal of clinical therapeutics and risk management, focusing on concise rapid reporting of clinical studies in all therapeutic areas, outcomes, safety, and programs for the effective, safe, and sustained use of medicines. This journal is indexed on PubMed Central, CAS,

EMBase, Scopus and the Elsevier Bibliographic databases. The manuscript management system is completely online and includes a very quick and fair peer-review system, which is all easy to use. Visit http://www.dovepress.com/testimonials.php to read real quotes from published authors.

Submit your manuscript here: http://www.dovepress.com/therapeutics-and-clinical-risk-management-journal 